\title{
Monosodium L-glutamate in soup reduces subsequent energy intake from high-fat savoury food in overweight and obese women
}

\author{
Takashi Miyaki*, Toshifumi Imada, Susan Shuzhen Hao and Eiichiro Kimura \\ North American Research and Innovation Center, Ajinomoto North America, Inc., 400 Kelby Street, Fort Lee, NJ O7024, USA \\ (Submitted 10 June 2015 - Final revision received 8 September 2015 - Accepted 10 September 2015 - First published online 12 October 2015)
}

\section{Abstract}

The umami seasoning, monosodium L-glutamate (MSG), has been shown to increase satiety in normal body weight adults, although the results have not been consistent. The satiety effect of MSG in overweight and obese adults has not been examined yet. The objective of the present study was to investigate the effect of MSG in a vegetable soup on subsequent energy intakes as well as food selection in overweight and obese adult women without eating disorders. A total of sixty-eight overweight and obese women (BMI range: $25 \cdot 0-39 \cdot 9 \mathrm{~kg} / \mathrm{m}^{2}$ ), otherwise healthy, were recruited to our study. A fixed portion $(200 \mathrm{ml})$ of control vegetable soup or the same soup with added MSG $(0.5 \mathrm{~g} / 100 \mathrm{ml})$ was provided 10 min before an ad libitum lunch and an ad libitum snack in the mid-afternoon. The control soup had equivalent amount of Na to the soup with added MSG. Energy intakes at the ad libitum lunch and ad libitum snack time after the soup preload were assessed using a randomised, double-blind, two-way cross-over design. The soup with MSG in comparison with the control soup resulted in significantly lower consumption of energy at lunch. The addition of MSG in the soup also reduced energy intake from high-fat savoury foods. The soup with MSG showed lower but no significant difference in energy intake at mid-afternoon. The addition of umami seasoning MSG in a vegetable soup may decrease subsequent energy intake in overweight and obese women who do not have eating disorders.

\section{Key words: Umami: Monosodium L-glutamate: Satiety: Energy intake: Food choice: Overweight and obese women}

The amino acid L-glutamate is primarily consumed when free, not bound to proteins, in its ionic form of monosodium L-glutamate (MSG), and it is known to elicit a distinguishable fifth taste termed umami ${ }^{(1)}$. MSG has been shown to improve the sensory characteristics of many different kinds of foods ${ }^{(2,3)}$ and has been commonly used as a flavour enhancer. Owing to the properties of glutamate salts, including MSG for taste and flavour, their addition to foods has been found to allow for $\mathrm{Na}$ reduction without killing the pleasantness of foods ${ }^{(4-6)}$.

MSG can potentially affect appetite and energy intake because of its effect of enhancing the palatability of foods. The effect of MSG supplementation on appetite and energy intake has long been the interest of food scientists, nutritionists and physiologists. It is possible that umami-rich foods containing certain amounts of umami substances may support the satiating properties of protein. The same way as sweets tend to signal high-energy sources in the food, umami may serve to signal the presence of amino acids and proteins in the diet ${ }^{(7)}$. The potential role of MSG on satiety is supported by the evidence that umami taste receptors and signalling molecules are expressed in cells of the gastrointestinal mucosa, which release satiety-related hormones ${ }^{(8,9)}$. In fact, several clinical studies in humans have already been conducted to examine the effect of
MSG on appetite and energy intake. In long-term clinical studies, where MSG was used to manipulate the palatability of various foods within a meal, it affected food selection, although there was no influence on sustained energy intake and body weight ${ }^{(10-12)}$. However, these studies were conducted in institutionalised elderly individuals with the attempt to improve their food intake and nutritional status, and thus may not represent the normal population.

Moreover, the number of clinical studies that have examined the acute effects of MSG on appetite and energy intake is limited, and their results are inconsistent. In one of the studies, the addition of MSG to a consommé preload did not show significant effects on subsequent appetite and energy intake ${ }^{(13)}$. In another study, MSG addition to a high-protein meal was shown to increase energy intake at the next meal, although no effect on appetite was observed ${ }^{(14)}$. However, the addition of MSG to low-energy chicken broth was found to decrease hunger and desire to snack. Its effect on energy intake did not reach a significant level ${ }^{(15)}$. Our recent study using a large sample size suggested that the addition of MSG to a low-energy chicken broth reduced the subsequent energy intake ${ }^{(16)}$. Furthermore, the combination of MSG with 5'-ribonucleotides of inosine monophosphate in carrot soup was found to

\footnotetext{
Abbreviations: MSG, monosodium L-glutamate; VAS, visual analogue scale.
} 
decrease subsequent energy intake ${ }^{(17)}$. According to these recent studies, it seems that MSG would reduce the postingestive recovery of hunger and enhance satiety.

Studies in rodents and humans have shown that the underlying molecular and neuronal mechanisms of energy metabolism and appetite control in obese conditions could be different from the mechanisms in a normal body weight condition ${ }^{(18-20)}$. Furthermore, obese women had lower taste sensitivity of MSG than normal weight women ${ }^{(21)}$. Although the acute effect of MSG on appetite rating and energy intake has been measured in healthy and normal body weight adults ${ }^{(15-17)}$, to date there have been no studies carried out on overweight and obese adults. There is a possibility that the effect of MSG on appetite rating and energy intake in overweight and obese adults is different from the effect in healthy and normal body weight adults.

The purpose of the present study was to investigate the effect that MSG in vegetable soup has on the energy intake in overweight and obese adults without eating disorders. We recruited overweight and obese females (BMI range: $25 \cdot 0-39.9 \mathrm{~kg} / \mathrm{m}^{2}$ ) without metabolic diseases and eating disorders. In the present study, subjective appetite, energy intake and food choice at an ad libitum lunch and an ad libitum snack in the mid-afternoon were measured after the soup preload with MSG. The same soup preloads were given twice a day. The study design was based on the previous study that showed the potential for accumulative effects of MSG preload on satiety in normal weight women using a double-preload design ${ }^{(15)}$. The first preload soup was given before lunch to assess the effect of MSG on energy intake. The second preload soup was given before the snack time to examine consumption of the MSG soup preload more than once a day on energy intake. To our knowledge, this is the first study to assess the acute impact of MSG in vegetable soup on subsequent energy intake and food choice in overweight and obese subjects without eating disorders. The main hypothesis was that the addition of MSG in vegetable soup preload would decrease total energy intake at the ad libitum lunch and at the ad libitum snack time. We also predicted that MSG would have an influence on food choice.

\section{Methods}

\section{Subjects}

The present study was conducted at Leatherhead Food Research (Leatherhead, Surrey, UK). Subjects were recruited from the Leatherhead Food Research's volunteer database using advertisements. Individuals who expressed an interest in the study were invited to an initial screening session and were asked to fill in screening questionnaires. Prospective subjects were selected on the basis of the data obtained from screening questionnaires. The selection criteria included the following: female, between 19 and 60 years of age, BMI ranging from 25 to $39.9 \mathrm{~kg} / \mathrm{m}^{2}$, non-smoking, non-heavy drinking, non-intense sporting activities, weight gain or loss of $<10 \%$ during the most recent 6 months, neither pregnant nor breast-feeding, free from food allergies, having neither current nor previous metabolic diseases and having no chronic gastrointestinal disorders. Furthermore, these individuals completed the sick, control, one, fat, food (SCOFF) questionnaire, which has been reported to have $100 \%$ sensitivity for the detection of individuals with eating disorders ${ }^{(22)}$. Individuals who had possible eating disorders as measured using an SCOFF questionnaire score of $>1$ or who answered 'yes' to two or more questions on the SCOFF questionnaire were excluded from the study.

Before the start of the study, subjects attended a compulsory information session in which they received detailed oral instructions. Subjects were given the complete set of instructions about the study, and they were also provided with dates as to when they should attend the Nutrition Unit at Leatherhead Food Research and take part in the study. Subjects were then familiarised with the completion of the visual analogue scale (VAS) for subjective ratings of satiety, and their height and weight were measured to determine their BMI $\left(\mathrm{kg} / \mathrm{m}^{2}\right)$. All the subjects signed the informed consent and were financially compensated for participating in the study. The study was conducted in accordance with the ethical principles set forth in the current version of the Declaration of Helsinki and the International Conference on Harmonization E6 Good Clinical Practice as well as all applicable UK regulatory requirement(s).

\section{Study design}

The present study used a randomised, double-blind, two-way cross-over design, which evaluated energy intake and satiety responses at lunch and mid-afternoon snack after the consumption of a control carrot and coriander soup compared with the same soup containing MSG $(0.5 \mathrm{~g} / 100 \mathrm{ml})$.

The qualified subjects visited the test facility of Leatherhead Food Research once a week for 3 weeks, $1 \mathrm{~d}$ for adaptation and $2 \mathrm{~d}$ for the test. The adaptation visit was incorporated into the study design so as to avoid first-order effects. On the day of the study, the subjects consumed a standard breakfast in the morning and the test soups before lunch and before mid-afternoon snacks. Throughout the day of the study, the subjects completed VAS questionnaires to determine subjective ratings of hunger, fullness and desire to eat.

\section{Composition of the preload}

The test preloads were produced by Leatherhead Food Research. The vehicle used to deliver the test preload was a carrot and coriander soup that consisted of salt, black pepper, carrot, onion, garlic, nutmeg, fresh coriander, $18 \%$ fat cream and vegetable stock. The carrot and coriander soup was packaged in individual portions $(200 \mathrm{ml})$ and frozen at $-20^{\circ} \mathrm{C}$. The vehicle was thawed for $24 \mathrm{~h}$ before consumption, and on the morning of the adaptation or the day of study an additional $1 \mathrm{~g}$ of MSG (Ajinomoto North America, Inc.) was added to the MSG preload. An additional $0.57 \mathrm{~g}$ of salt was added to the control preload in order to adjust the amount of $\mathrm{Na}$, so that both the samples have equal levels of $\mathrm{Na}$. The two preloads tested in this study were of the same energetic value $(196.6 \mathrm{~kJ})$ and of equal weight. All preparation methods were standardised in order to ensure that the test preloads were of the same consistency for every subject. Table 1 lists the test preload characteristics. 
Table 1. Composition of test soup

\begin{tabular}{lcc}
\hline & Control & MSG \\
\hline Serving (ml) & 200 & 200 \\
Energy (kJ) & 195 & 195 \\
Protein (g) & 0.78 & 0.78 \\
Carbohydrate (g) & 5.46 & 5.46 \\
Fat (g) & 1.95 & 1.95 \\
MSG (g) & 0 & 1 \\
Total Na (mg) & 500 & 500 \\
\hline
\end{tabular}

MSG, monosodium L-glutamate.

Table 2. Lunch buffet properties (all data are per $100 \mathrm{~g}$ )

\begin{tabular}{|c|c|c|c|c|}
\hline Lunch buffet items & $\begin{array}{l}\text { Energy } \\
\text { (kJ) }\end{array}$ & $\begin{array}{l}\text { Protein } \\
\text { (g) }\end{array}$ & $\begin{array}{l}\text { Carbohydrate } \\
\text { (g) }\end{array}$ & $\begin{array}{l}\text { Fat } \\
\text { (g) }\end{array}$ \\
\hline \multicolumn{5}{|l|}{ High-fat savoury } \\
\hline Soft cheese & 995 & 6 & $2 \cdot 4$ & 23 \\
\hline Chicken nuggets & 1032 & $16 \cdot 2$ & 18.5 & 11.5 \\
\hline Houmous & 1315 & $7 \cdot 4$ & 4.9 & $26 \cdot 8$ \\
\hline $\begin{array}{l}\text { Lurpak Spreadable Lighter, } \\
\text { unsalted }\end{array}$ & 2250 & 0.4 & 0.4 & 60 \\
\hline \multicolumn{5}{|l|}{ Low-fat savoury } \\
\hline White bread & 1007 & 9 & $44 \cdot 6$ & 2 \\
\hline Wholemeal roll & 980 & $10 \cdot 6$ & $38 \cdot 8$ & $3 \cdot 8$ \\
\hline Roast turkey chunks & 453 & $22 \cdot 3$ & $2 \cdot 6$ & 0.8 \\
\hline Carrot sticks & 108 & 0.6 & 4.9 & 0.4 \\
\hline Mixed salad leaves & 93 & 1.5 & $3 \cdot 4$ & 0.3 \\
\hline \multicolumn{5}{|l|}{ High-fat sweet } \\
\hline Chocolate chip cookies & 2005 & $5 \cdot 6$ & $64 \cdot 2$ & $22 \cdot 1$ \\
\hline Flapjack Fingers & 2035 & $6 \cdot 5$ & $60 \cdot 8$ & 23.4 \\
\hline Dairy Milk chocolate & 2200 & $7 \cdot 5$ & 57 & $29 \cdot 8$ \\
\hline \multicolumn{5}{|l|}{ Low-fat sweet } \\
\hline Braeburn apple & 199 & 0.4 & $11 \cdot 8$ & $0 \cdot 1$ \\
\hline Grapes & 257 & 0.4 & $15 \cdot 4$ & $0 \cdot 1$ \\
\hline Strawberry jelly, ready to eat & 340 & 0 & 20 & 0 \\
\hline Low-fat yogurt & 285 & 5.5 & $7 \cdot 8$ & 1.5 \\
\hline
\end{tabular}

\section{Breakfast, test lunch and snack buffet composition}

Subjects were provided with their habitual portion of cornflakes and semi-skimmed milk for breakfast. On their first visit, subjects were given a 500-g box of cereal and a 500-ml carton of milk and were asked to consume the quantity they would normally have for breakfast. The cereal box was then weighed and given to the participants on their subsequent test days. This created a self-regulated standardised baseline, meaning that all the participants felt satiated to their usual level after breakfast.

The test lunch buffet consisted of sixteen foods varying in taste and fat content with a total energy amount of $15564 \cdot 4 \mathrm{~kJ}$ ). There were four high-fat savoury foods, five low-fat savoury foods, three high-fat sweet foods and four low-fat sweet foods. Test snacks consisted of sixteen snacks varying in taste and fat content with a total energy amount of $20731.7 \mathrm{~kJ}$. There were four high-fat savoury foods, four low-fat savoury foods, four high-fat sweet foods and four low-fat sweet foods. Tables 2 and 3 show the lunch and snack buffet composition.

All lunch and snack buffets were weighed before being served to the subjects, and were re-weighed after the subjects had finished eating to determine the amount of each food consumed. Energy and nutrient intakes were calculated using
Table 3. Snack buffet properties (all data are per $100 \mathrm{~g}$ )

\begin{tabular}{|c|c|c|c|c|}
\hline Snack buffet items & $\begin{array}{c}\text { Energy } \\
(\mathrm{kJ})\end{array}$ & $\begin{array}{l}\text { Protein } \\
\text { (g) }\end{array}$ & $\begin{array}{c}\text { Carbohydrate } \\
\text { (g) }\end{array}$ & $\begin{array}{l}\text { Fat } \\
(\mathrm{g})\end{array}$ \\
\hline \multicolumn{5}{|l|}{ High-fat savoury } \\
\hline Ready salted crisps & 2241 & $5 \cdot 9$ & $49 \cdot 7$ & $34 \cdot 1$ \\
\hline $\begin{array}{l}\text { Medium Cheddar } \\
\text { cheese }\end{array}$ & 1619 & $25 \cdot 5$ & 0.1 & 32 \\
\hline Sausage rolls & 1359 & 9 & $27 \cdot 1$ & $19 \cdot 7$ \\
\hline Tesco salted popcorn & 2220 & 9.4 & $50 \cdot 4$ & $31 \cdot 1$ \\
\hline \multicolumn{5}{|l|}{ Low-fat savoury } \\
\hline Soft white rolls & 1068 & 8.9 & $46 \cdot 7$ & $2 \cdot 8$ \\
\hline Cottage cheese & 265 & 9.5 & 5 & 0.5 \\
\hline Boiled egg & 612 & 12.5 & 0 & $10 \cdot 8$ \\
\hline $\begin{array}{l}\text { Sainsbury's water } \\
\text { biscuits }\end{array}$ & 1742 & $10 \cdot 1$ & 75 & $7 \cdot 1$ \\
\hline \multicolumn{5}{|l|}{ High-fat sweet } \\
\hline Blueberry muffin & 1630 & 4.9 & $48 \cdot 3$ & $19 \cdot 6$ \\
\hline Biscuits & 2003 & $7 \cdot 1$ & 60.9 & 21.7 \\
\hline Carrot cake slices & 1642 & $3 \cdot 4$ & 61 & $14 \cdot 3$ \\
\hline Dairy Milk chocolate & 2200 & $7 \cdot 5$ & 57 & $29 \cdot 8$ \\
\hline \multicolumn{5}{|l|}{ Low-fat sweet } \\
\hline Banana & 414 & $1 \cdot 2$ & $22 \cdot 5$ & 0.3 \\
\hline Marshmallows & 1422 & $3 \cdot 4$ & 80 & 0.1 \\
\hline Cocktail in juice & 205 & 0.5 & $11 \cdot 2$ & 0.1 \\
\hline Jelly Babies & 1420 & $3 \cdot 6$ & $79 \cdot 8$ & 0 \\
\hline
\end{tabular}

nutritional information provided by the manufacturer's food labels on each food package.

\section{Appetite motivational ratings and test preload characteristics ratings}

Both appetite motivational ratings and test preload characteristics ratings were assessed using a 100-mm electronic VAS on hand-held computers (iPAQ; Hewlett-Packard Development Company, L.P.), which prompted subjects for a response in a pre-programmed manner. The questions (e.g. 'How hungry are you right now?') were anchored at opposite ends of the 100-mm horizontal line by 'not hungry at all' and 'extremely hungry', and all the subjects were asked to make a straight vertical mark to indicate how they felt at that moment. Appetite motivational questions included fullness, hunger, thirst and desire to eat. Test preload characteristics ratings included ratings of the basic tastes of salty, sweet and creamy, as well as hedonic properties of satisfaction and liking. Scores were collected so that subjects could not refer to their previous ratings of appetite motivational questions and test preload characteristics.

\section{Study procedure}

Fig. 1 shows the study timeline of the test day. Subjects were asked to maintain their normal lifestyle the day before the study, but were asked to consume their evening meal no later than 20.00 hours; this should have consisted of margherita pizza and garlic bread. Subjects were also asked to abstain from alcohol and vigorous exercise for $24 \mathrm{~h}$ before each test. Only drinking water was allowed after 20.00 hours. Subjects were asked to refrain from drinking any liquids for $1 \mathrm{~h}$ before the start of the study day. Subjects were instructed to record everything they 


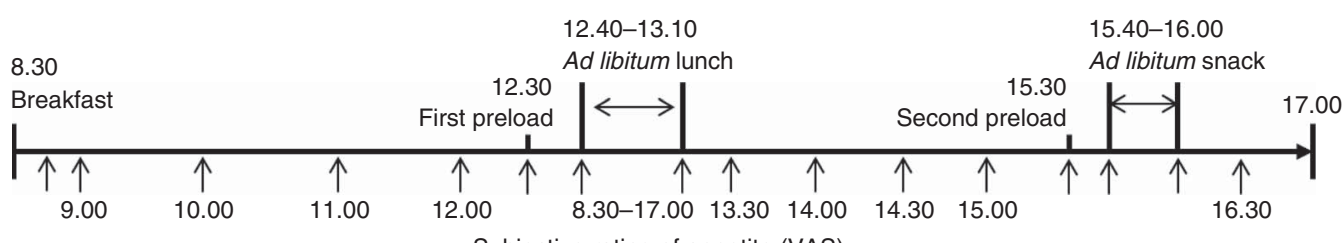

Subjective rating of appetite (VAS)

Fig. 1. Study timeline of the test day. VAS, visual analogue scale.

consumed between 18.00 and 20.00 hours. Food and drink consumption from their evening meal onwards before the test was recorded before each subsequent test visit.

On the study day, subjects were instructed to arrive at the test facility of Leatherhead Food Research no later than 8.15 hours. Subjects were seated in booths to isolate them from each other. Immediately before consumption of breakfast at 8.30 hours, subjects completed the baseline ratings for appetite motivation, after they were served their habitual portion of cornflakes and semi-skimmed milk for breakfast. Subjects were given $15 \mathrm{~min}$ to eat the breakfast, and immediately after consumption ( 8.45 hours) they filled the questionnaires on appetite motivation. When they finished, the subjects were free to leave the booths. Subjects were asked to remain in the test facility of Leatherhead Food Research for the rest of the day. Consumption of water was allowed during the test day; however, consumption was restricted to $150 \mathrm{ml} / \mathrm{h}$. To ensure that similar conditions existed during each test day, the consumption of water during the first test was recorded as well as at each subsequent test.

At 12.30 hours, subjects received their first portion of the test preload soup that had to be completely consumed in $10 \mathrm{~min}$. During the consumption, participants were asked to complete paper VAS questionnaires on the taste characteristics of the preload. Immediately after consumption (12.40 hours), questionnaires on appetite motivation were completed, after which the subjects were provided with an ad libitum buffet lunch consisting of a variety of savoury and sweet foods. Subjects were given $30 \mathrm{~min}$ to consume as much food as they liked until they felt comfortably full, in silence, without any distractions. After $30 \mathrm{~min}$ (13.10 hours), questionnaires on appetite motivation were answered, after which the subjects were free to leave the booths. At 15.30 hours, subjects received their second portion of the test preload soup, which was the same as the first test preload soup, and were given $10 \mathrm{~min}$ to consume it all. Again, during consumption, subjects were asked to complete paper VAS questionnaires on the taste characteristics of the preload. Immediately after consumption ( 15.40 hours), questionnaires on appetite motivation were completed, after which the subjects were provided with an ad libitum snack buffet and were instructed to eat within a 20-min period until they felt comfortably full. Immediately after consumption of the snack buffet (16.00 hours), subjects were asked to answer questionnaires on appetite motivation and then at 30-min intervals for $1 \mathrm{~h}$ until the end of the test day, after which the subjects were free to leave the test facility. Appetite motivational ratings were also taken at 9.00, $10.00,11.00,12.00,13.30,14.00,14.30$ and 15.00 hours. Concomitant medication uses and adverse events were recorded.
Table 4. Subject characteristics (Mean values with their standard errors)

\begin{tabular}{lcl}
\hline & Mean & SEM \\
\hline Age (years) & 38.8 & 1.2 \\
BMI $\left(\mathrm{kg} / \mathrm{m}^{2}\right)$ & 28.6 & 0.44 \\
SCOFF & 0.1 & 0.04 \\
BDI & 2.1 & 0.27 \\
\hline
\end{tabular}

SCOFF, sick, control, one, fat, food questionnaire; BDI, Beck Depression Inventory.

\section{Statistical analysis}

Data are presented as means with their standard errors unless stated otherwise. Statistical analyses were carried out using STATA, version 12 (StataCorp LP). Normality of data distribution was studied using $\gamma-3$ and $\gamma-4$ distribution parameters. Ratings of soup preload characteristics were analysed by the Wilcoxon matchedpairs signed-rank test as the distribution of the parameters was found to be significantly deviant from the normal distribution. The Wilcoxon matched-pairs signed-rank test was also applied for the analysis of differences in lunch, snack and total energy intake after consumption of each soup. Appetite motivational ratings were analysed using a repeated-measures ANOVA with preload soup (two preload types) and time (eleven ratings from 12.30 to 17.00 hours) as the within-subject factors, as population distributions of appetite motivational ratings were normally distributed. Statistical significance was defined as $P<0.05$ in all comparisons.

\section{Study power and sample size}

Sample size calculation was based on a standard formula ${ }^{(23)}$ obtained from a pilot study carried out by Leatherhead Food Research. A sample of sixty-three subjects was sufficient to detect a difference with a power of $80 \%$ and $\alpha=0 \cdot 05$.

\section{Results}

\section{Subjects}

In total, seventy-one healthy female individuals were recruited and successfully completed the study. Based on the inclusion criteria, three subjects were excluded because of protocol deviations and concomitant medication use; thus, a total of sixtyeight subjects were included in the data analysis. The characteristics of the subjects are shown in Table 4. The subjects were overweight and obese (mean BMI: 28.6 (sem 0.44) kg/m²) and had no eating disorders (SCOFF: 0.1 (SEM 0.04)). No adverse responses against the soup samples were observed during the study. 


\section{Rating of carrot and coriander soup preload characteristics}

Subjects were not trained for the basic tastes. There were no significant differences in saltiness between the two preload soups and between the various time intervals (Fig. 2(a)). A significant reduction in sweetness over time was observed in the control soup (Fig. 2(b); $P=0.002$ ); no significant differences in sweetness between the two soups were observed at the first or second preload session (12.30 or 15.30 hours). The creaminess rating was higher in the MSG soup group for the first preload (12.30 hours); however, this difference was absent at the second preload (15.30 hours; Fig. 2(c)). A significant change in satisfaction was observed in both the groups between the first and second preloads (Fig. 2(d)). The rating of satisfaction increased after consumption of the control soup ( $P=0.046)$, whereas the rating after consumption of the MSG soup decreased $(P=0 \cdot 015)$. Satisfaction was significantly higher in the MSG soup group at the first preload (12.30 hours; $P=0 \cdot 012$ ); however, this significant difference was lost at the second preload (15.30 hours). A significant reduction in liking was observed over time in both the groups (Fig. 2(e)). No significant differences in liking between the two groups were observed at the first or the second preload (12.30 or 15.30 hours).

\section{Effects of the preloads on subsequent energy intake}

The Wilcoxon matched-pairs signed-rank test was applied for the analysis of differences in energy intake after consumption of either the MSG soup preload or the control soup preload.
This was due to the distribution in outcome being significantly skewed in a substantial proportion of parameters. For total energy intake, the outcome of the Shapiro-Wilk test is provided, because for all energy results determined a significant number of parameters was found to be not normally distributed.

The energy intake was significantly less $(216 \cdot 3 \mathrm{~kJ})$ during lunch after an MSG soup preload compared with a control soup preload (Table $5 ; P=0 \cdot 014$ ). There was no significant difference in energy intake at snack time after a preload of two soups $(P=0.505)$; however, the MSG soup preload had the potential to decrease total energy intake compared with the control soup preload $(P=0.057)$.

The energy intake from high-fat savoury foods was significantly decreased at lunch $(P=0.045)$, at snack time $(P=0.004)$ and in total $(P=0.004)$ after consumption of the MSG preload (Fig. 3(a)). However, the MSG soup preload did

Table 5. Energy intake

(Mean values with their standard errors)

\begin{tabular}{llllll}
\hline & \multicolumn{2}{c}{ Control (kJ) } & & \multicolumn{2}{c}{ MSG (kJ) } \\
\cline { 2 - 3 } \cline { 6 - 7 } & Mean & SEM & & Mean & SEM \\
\hline Lunch & 3962 & 155 & & $3745^{*}$ & 146 \\
Snacks & 2598 & 150 & & 2477 & 138 \\
Total & 6561 & 259 & & 6224 & 259 \\
\hline
\end{tabular}

MSG, monosodium L-glutamate.

${ }^{*} P<0.05$ in comparison with control.

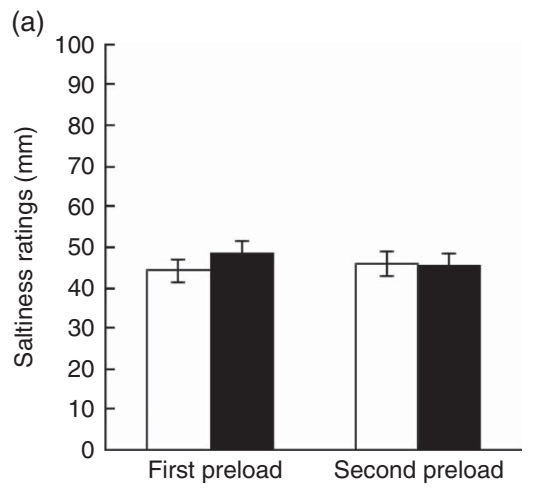

(b)

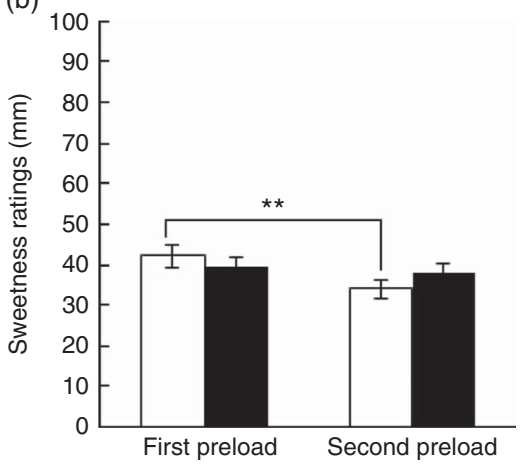

(e)

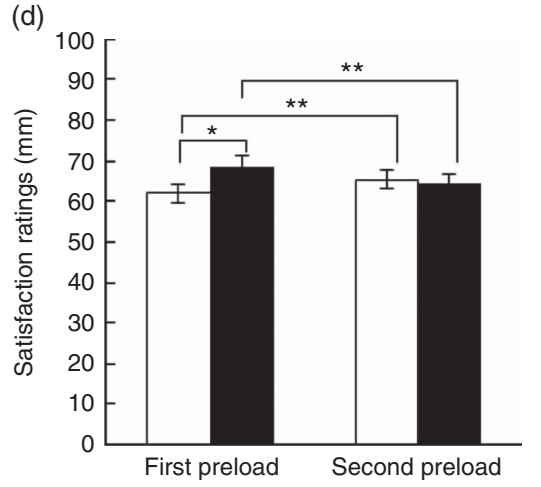

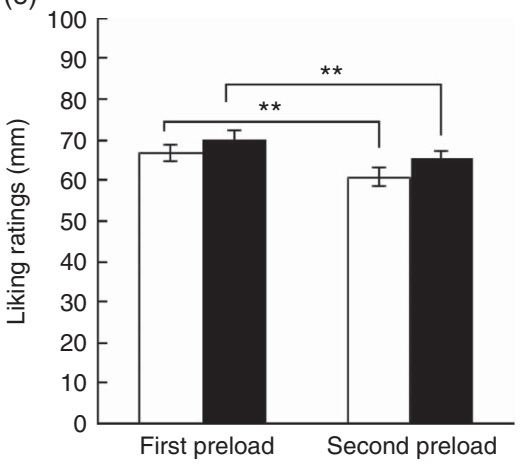

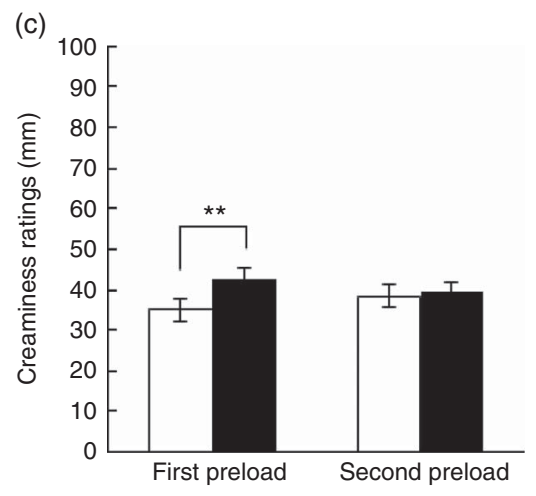

Fig. 2. Effect of monosodium L-glutamate (MSG) supplementation on test soup characteristics at each preload: (a) saltiness, (b) sweetness, (c) creaminess, (d) satisfaction and (e) liking. All ratings were taken using a 100-mm visual analogue scale at the time when the preload was consumed. Values are means, with standard errors represented by vertical bars. Ratings of soup preload characteristics were analysed by the Wilcoxon matched-pairs signed-rank test. Mean values were significantly different from those of the control group: ${ }^{*} P<0.05$; ${ }^{\star \star} P<0.01$. $\square$, Control; $\square$, MSG. 
(a)

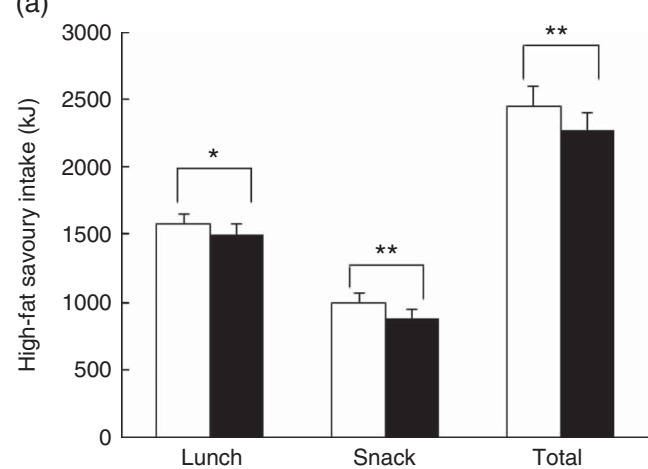

(c)

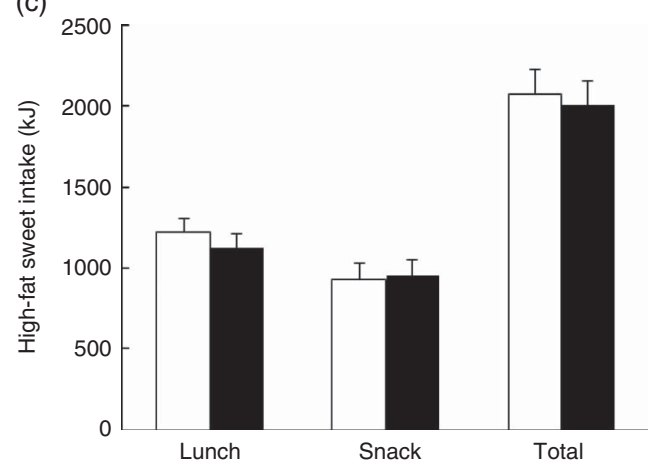

(b)

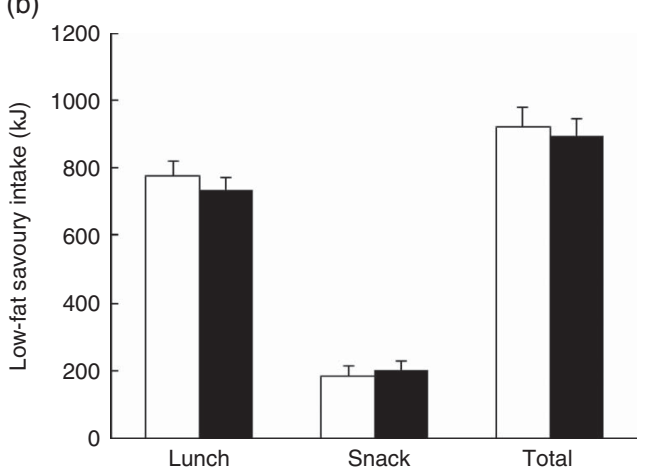

(d)

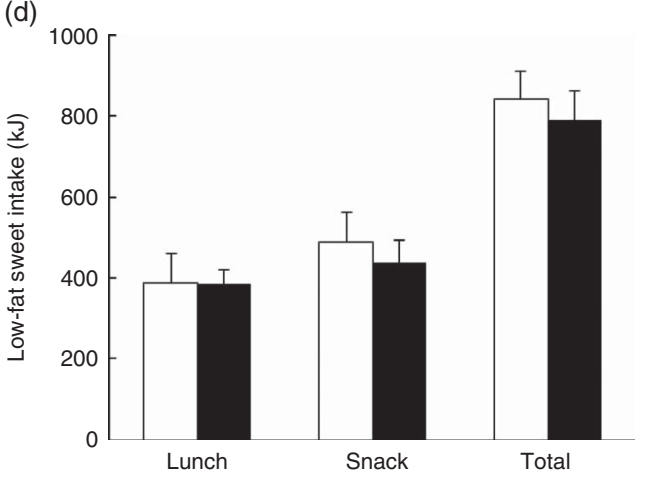

Fig. 3. Effect of monosodium L-glutamate (MSG) supplementation to the test soup preload on energy intake from (a) high-fat savoury foods, (b) low-fat savoury foods, (c) high-fat sweet foods and (d) low-fat sweet foods. Values are means, with standard errors represented by vertical bars. Energy intakes from lunch, snacks at midafternoon and in total from each category of food were analysed by the Wilcoxon matched-pairs signed-rank test. Mean values were significantly different from those of the control group: ${ }^{*} P<0.05 ;{ }^{* *} P<0.01$. $\square$, Control; $\square$, MSG.

not affect low-fat savoury intakes at lunch $(P=0 \cdot 280)$, at snack time $(P=0.116)$ or in total (Fig. 3(b); $P=0.537)$. No significant difference in energy intake from high- or low-fat sweet foods was observed at lunch, at snack time or in total following a preload of control or MSG soup (Fig. 3(c) and (d)).

\section{Subjective appetite motivational ratings}

For fullness ratings, there was a significant effect of time $(P<0.001)$ and a significant effect of two soup preloads ( $P=0.013$ ) over the period of intervention (12.30-17.00 hours), with the control group showing higher feelings of subjective fullness (Fig. 4(a)). However, there was no noticeable interaction between soup and time. Similarly, ratings of hunger showed a significant effect of time $(P<0 \cdot 001)$ and a significant effect of two soup preloads $(P=0.013)$ over the period of intervention (12.30-17.00 hours), with the control group showing lower feelings of subjective hunger (Fig. 4(b)); however, again, there was no noticeable interaction between soup and time.

Ratings for desire to eat and thirst were also not different across the two preload conditions during the intervention period (data not shown). No adverse events due to the test product were reported.

\section{Discussion}

The present study describes a double-blind, cross-over study with sixty-eight overweight and obese women without eating disorders, whose BMI ranged from 25.0 to $39.9 \mathrm{~kg} / \mathrm{m}^{2}$, in whom subjective appetite rating, energy intake and food selection were evaluated in an ad libitum lunch and mid-afternoon snack test meal following a vegetable soup preload with or without MSG. The addition of MSG to the soup enhanced the perception of creaminess, and is in agreement with our recent study that the addition of MSG enhanced satisfaction ${ }^{(16)}$. Major findings indicate that, compared with a control soup preload, an MSG soup preload significantly decreased energy intake during lunch and also showed a trend towards reduction in total energy intake in overweight and obese women without eating disorders $(P=0.056)$. Furthermore, energy intake from high-fat savoury foods was significantly lower at lunch, at snack time and in total $(P=0.004)$ after consumption of an MSG soup preload. This is the first study to show that MSG in a vegetable soup preload reduced subsequent energy intake in overweight and obese women without eating disorders, which has also been observed in healthy normal body weight women ${ }^{(16)}$.

Studies carried out in rodents and humans have shown that obesity could affect the regulation of appetite in conjunction with a change in energy metabolism ${ }^{(18-20)}$. Therefore, we investigated the effect of MSG on energy intake when added to a vegetable soup among overweight and obese women without eating disorders. The first MSG soup preload significantly reduced energy intake at the ad libitum lunch in overweight and obese women, which agrees with our previous study in normal body weight women ${ }^{(16)}$. This suggests that the effect of MSG on subsequent energy intake may not be affected by body 
(a)

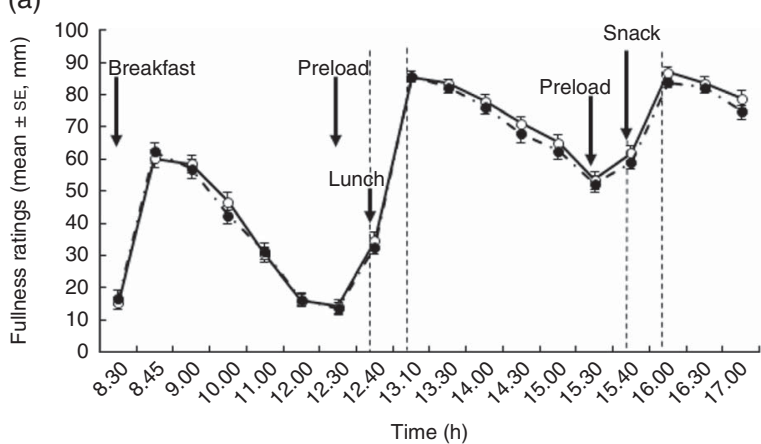

(b)

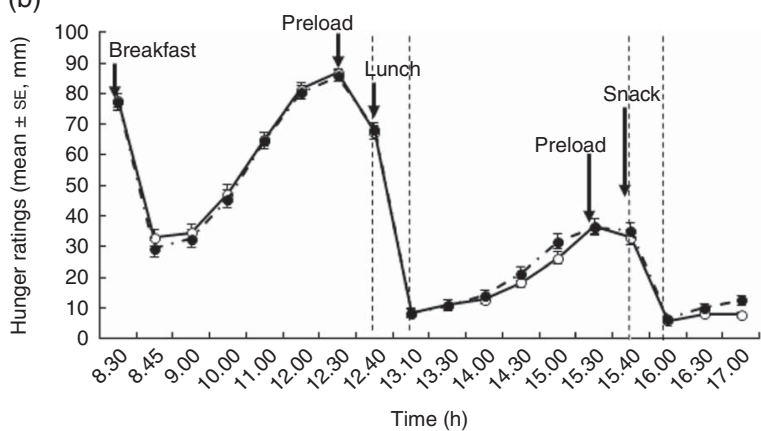

Fig. 4. Temporal profiles of (a) fullness and (b) hunger ratings during the study period in two conditions. All ratings were taken using a $100-\mathrm{mm}$ visual analogue scale. The arrow indicates the point when the standard breakfast, test preload, lunch or snacks was served to the subject. Appetite motivational ratings were analysed using a repeated-measures ANOVA with preload soup (two preload types) and time (eleven ratings from 12.30 to 17.00 hours) as the within-subject factors. Values are means, with standard errors. $\multimap-$, Control; -•-, monosodium L-glutamate.

weight if obese subjects do not have eating disorders. The second MSG soup preload did not significantly reduce the energy intake at the ad libitum snack time. However, this result may imply the effect of the second MSG soup preload, because energy compensation was not found after the lower energy consumption at the ad libitum lunch. A previous study with double-preload design in normal body weight women showed the potential of the accumulative effect of MSG preload on the feeling of satiety ${ }^{(15)}$. In this study, snack intake after the second MSG soup preload was reduced by $120 \mathrm{~kJ}$ on average. In both the studies, although there was no significant difference, MSG showed a potential to reduce energy intake. The appetite rating was different from the previous study. Further studies will be needed to validate these results; however, this phenomenon indicates that repetitive exposure to MSG may contribute to overall reduction of energy intake in overweight and obese women without eating disorders throughout the day.

The present study also showed that a vegetable soup with MSG suppressed energy intake from high-fat savoury foods. One possible explanation is that consumption of the higher savoury soup with added MSG may lead to decreased subsequent energy intake from savoury foods. Finlayson $e t a l^{(2)}$ investigated beverage preloads with difference in taste on subsequent test meals. They found that savoury preloads, with their savouriness enhanced using MSG, reduced the intake of high-fat savoury foods more than sweet or bland preloads ${ }^{(24)}$, which is consistent with the present study. On the other hand, our recent study showed that the addition of MSG into a chicken broth preload suppressed energy intake from high-fat and sweet snacks but not from savoury snacks in normal weight women ${ }^{(16)}$. Thus, the number of studies that have examined how MSG influences food choice is limited and the results are not conclusive. Further studies are needed to investigate whether preloads with MSG can have an effect on subsequent food selection.

The preload of vegetable soup with MSG decreased subjective ratings of fullness and increased the sensation of hunger during the period of intervention (12.30-17.00 hours). One possible explanation is the lower energy intake at ad libitum lunch after MSG supplementation. In general, there are positive relationships between hunger and the energy intake; however, there was no difference in energy intake at the ad libitum snack time between the control and the MSG preload group, although the soup with MSG increased hunger ratings during the intervention period. Consistent with the present study, Rogers \& Blundell ${ }^{(13)}$ reported that higher hunger ratings for the soup preload with MSG did not lead to higher energy intakes. On the other hand, Imada et al. ${ }^{(1)}$ showed lower energy intake following soup preload with MSG, although hunger ratings with the MSG preload were the same as that with the control preload. Some other studies have also indicated that lower hunger ratings after a test preload did not lead to lower energy intake at a subsequent meal ${ }^{(15,25)}$. Thus, subjective appetite ratings have not always been consistent with subsequent energy intake.

In the present study, energy intakes at an ad libitum lunch and ad libitum snack time were examined 10 min after soup preloads. It has been reported that both taste and post-ingestive effects contribute to subsequent energy intakes when energy intake at a meal is investigated within $30 \mathrm{~min}$ after test preloads ${ }^{(26)}$. Available evidence, at least, leads to suggest the possibility of post-ingestive effects of MSG on food intake. Glutamate signalling molecules are reported to be expressed in a variety of enteroendocrine cells within the gut wall ${ }^{(8,9)}$ and application of glutamate stimulates the afferent vagal fibres of the gastric branch and activates distinct forebrain regions via vagal nerves ${ }^{(27,28)}$. Moreover, the application of glutamate to intestinal tissue explants in rodents induces the secretion of the satiety-related hormone cholecystokinin, whereas in humans glucagon-like peptide-1 (GLP-1) release increased after MSG ingestion ${ }^{(29,30)}$, although these results are inconclusive. On the other hand, the effect of the oral cavity on food intake after ingestion of food with MSG has not been examined well. The first MSG preload was perceived to be significantly higher in creaminess than the control preload; moreover, subjects were more satisfied with the first MSG preload, which may be associated with the reduction in energy intake at the subsequent ad libitum lunch. Thus, MSG signalling in the oral cavity may also be involved in subsequent energy intake after ingestion of food with MSG; however, further studies are necessary to clarify the mechanism.

There are a number of limitations to the present study. The purpose of this study was to investigate the effect of MSG, in the 
form of a soup preload, on energy intake and food choice at a subsequent lunch and at mid-afternoon snack among overweight and obese adults without eating disorders. The first limitation was the sequence of food presentation of having soup not only $10 \mathrm{~min}$ before lunch but also $10 \mathrm{~min}$ before snack time, which does not represent a normal setting. We do not usually consume soup twice $10 \mathrm{~min}$ before lunch or $10 \mathrm{~min}$ before snacking; thus, the effect of MSG described here might not be directly applicable for everyday eating situations. Although this study was designed not only to assess the single effect of the MSG soup preload but also to examine consumption of the MSG soup preload more than once a day on energy intake in overweight and obese adults without eating disorders, it seems important to further investigate the effect of MSG using protocols that are more representative of daily eating situations such as serving soup at lunch. The second limitation was that the study design only assessed the effect of MSG soup preload on energy intake for a short time. Further studies will be required to investigate whether MSG preload has the potential to decrease energy intake in overweight and obese adults without eating disorders for a long time. In addition to the present study, a few reports have also suggested that MSG soup preload may induce satiety in healthy adults for a short time ${ }^{(17,31)}$. Taking the results of these clinical studies as well as the evidence suggesting the possibility of post-ingestive effects of MSG into consideration $^{(27,28)}$, the effect of MSG on energy intake reduction may be expected after offering the MSG soup preload for a longer period; however, to date, there have been no studies investigating the long-term effects. Another limitation was that only female subjects were included in the study. Although this study was carried out on overweight and obese females with the intention to minimise variability on energy intake $^{(15,16)}$, further studies including both the sexes should be performed.

In conclusion, the addition of MSG to a vegetable soup decreased subsequent energy intake in healthy overweight and obese women without eating disorders. Addition of MSG also influenced food selection by reducing the intake of high-fat savoury foods. These findings indicate that soups rich in umami compounds such as MSG as a preload may lead to healthier food choices and contribute to appropriate energy intake in overweight and obese women without eating disorders.

\section{Acknowledgements}

The authors sincerely thank Roberta Re, Carmen Diaz-Toledo and Sonia Pombo of Leatherhead Food Research for their conduct of the study and valuable discussion for study design as well as for valuable comments on this manuscript. The authors are grateful to Kunio Torii for encouragement and support of this work.

T. M. interpreted the results and drafted the manuscript. T. I. designed the study, managed the execution of the experimental work and analysed the data. S. S. H. provided comments on the design, management of execution and interpretation of the results. E. K. provided comments on both the design and the manuscript.

There are no conflicts of interest to declare.

\section{References}

1. Ikeda K (2002) New seasonings. Chem Senses 27, 847-849.

2. Prescott J (2004) Effects of added glutamate on liking for novel food flavors. Appetite 42, 143-150.

3. Yamaguchi S \& Ninomiya K (2000) Umami and food palatability. J Nutr 130, 921S-926S.

4. Carter BE, Monsivais P \& Drewnowski A (2011) The sensory optimum of chicken broths supplemented with calcium di-glutamate: a possibility for reducing sodium while maintaining taste. Food Qual Prefer 22, 699-703.

5. Okiyama A \& Beauchamp GK (1998) Taste dimensions of monosodium glutamate (MSG) in a food system: role of glutamate in young American subjects. Physiol Behav 65, 177-181.

6. Roininen K, Lahteenmaki L \& Tuorila H (1996) Effect of umami taste on pleasantness of low-salt soups during repeated testing. Physiol Behav 60, 953-958.

7. Chaudhari N \& Roper SD (2010) The cell biology of taste. J Cell Biol 190, 285-296.

8. Nakamura E, Hasumura M, San Gabriel A, et al. (2010) New frontiers in gut nutrient sensor research: luminal glutamatesensing cells in rat gastric mucosa. J Pharmacol Sci 112, 13-18.

9. San Gabriel AM, Maekawa T, Uneyama H, et al. (2007) mGluR1 in the fundic glands of rat stomach. FEBS Lett 581, 1119-1123.

10. Bellisle F, Monneuse MO, Chabert M, et al. (1991) Monosodium glutamate as a palatability enhancer in the European diet. Physiol Behav 49, 869-873.

11. Essed NH, Kleikers S, van Staveren WA, et al. (2009) No effect on intake and liking of soup enhanced with mono-sodium glutamate and celery powder among elderly people with olfactory and/or gustatory loss. Int J Food Sci Nutr 60, Suppl. 5, 143-154.

12. Toyama K, Tomoe M, Inoue $\mathrm{Y}$, et al. (2008) A possible application of monosodium glutamate to nutritional care for elderly people. Biol Pharm Bull 31, 1852-1854.

13. Rogers PJ \& Blundell JE (1990) Umami and appetite: effects of monosodium glutamate on hunger and food intake in human subjects. Physiol Behav 48, 801-804.

14. Luscombe-Marsh ND, Smeets AJ \& Westerterp-Plantenga MS (2009) The addition of monosodium glutamate and inosine monophosphate- 5 to high-protein meals: effects on satiety, and energy and macronutrient intakes. Br J Nutr 102, 929-937.

15. Carter BE, Monsivais P, Perrigue MM, et al. (2011) Supplementing chicken broth with monosodium glutamate reduces hunger and desire to snack but does not affect energy intake in women. Br J Nutr 106, 1441-1448.

16. Imada T, Hao SS, Torii K, et al. (2014) Supplementing chicken broth with monosodium glutamate reduces energy intake from high fat and sweet snacks in middle-aged healthy women. Appetite 79, 158-165.

17. Masic U \& Yeomans MR (2014) Umami flavor enhances appetite but also increases satiety. Am J Clin Nutr 100, 532-538.

18. Denis GV \& Obin MS (2013) 'Metabolically healthy obesity': origins and implications. Mol Aspects Med 34, 59-70.

19. Jauch-Chara K \& Oltmanns KM (2014) Obesity - a neuropsychological disease? Systematic review and neuropsychological model. Prog Neurobiol 114, 84-101.

20. Yue JT \& Lam TK (2012) Lipid sensing and insulin resistance in the brain. Cell Metab 15, 646-655.

21. Pepino MY, Finkbeiner S, Beauchamp GK, et al. (2010) Obese women have lower monosodium glutamate taste sensitivity and prefer higher concentrations than do normalweight women. Obesity (Silver Spring) 18, 959-965. 
22. Morgan JF, Reid F \& Lacey JH (1999) The SCOFF questionnaire: assessment of a new screening tool for eating disorders. BMJ 319, 1467-1468.

23. Rosner B (2000) Fundamentals of Biostatistics, 5th ed. [C Crocket, editor]. Pacific Grove, CA: Brooks/Cole.

24. Finlayson G, Bordes I, Griffioen-Roose S, et al. (2012) Susceptibility to overeating affects the impact of savory or sweet drinks on satiation, reward, and food intake in nonobese women. J Nutr 142, 125-130.

25. El Khoury D, Goff HD, Berengut S, et al. (2014) Effect of sodium alginate addition to chocolate milk on glycemia, insulin, appetite and food intake in healthy adult men. Eur J Clin Nutr 68, 613-618.

26. Livingstone BE, Robson PJ, Welch RW, et al. (2000) Methodological issues in the assessment of satiety. Scand J Nutr 44, 98-103.

27. Tsurugizawa T, Uematsu A, Nakamura E, et al. (2009) Mechanisms of neural response to gastrointestinal nutritive stimuli: the gut-brain axis. Gastroenterology 137, 262-273.

28. Uneyama H, Niijima A, San Gabriel A, et al. (2006) Luminal amino acid sensing in the rat gastric mucosa. Am J Physiol Gastrointest Liver Physiol 291, G1163-G1170.

29. Daly K, Al-Rammahi M, Moran A, et al. (2013) Sensing of amino acids by the gut-expressed taste receptor T1R1-T1R3 stimulates CCK secretion. Am J Physiol Gastrointest Liver Physiol 304, G271-G282.

30. Hosaka H, Kusano M, Zai H, et al. (2012) Monosodium glutamate stimulates secretion of glucagon-like peptide- 1 and reduces postprandial glucose after a lipid-containing meal. Aliment Pharmacol Ther 36, 895-903.

31. Masic U \& Yeomans MR (2013) Does monosodium glutamate interact with macronutrient composition to influence subsequent appetite? Physiol Behav 116-117, 23-29. 